\title{
Applied mathematics as a tool for studying the efficiency of an enterprise
}

\author{
Marina Vinogradova*, and Liubov Iakodiuk \\ Northern Trans-Ural State Agricultural University, Republic St., 7, Tyumen, 625003, Russia
}

\begin{abstract}
This article discusses the application of applied mathematics in the study of the effectiveness of the enterprise of small forms of entrepreneurship individual entrepreneur Glukhikh L. P. The authors have identified the factors that most significantly affect the result of the enterprise-profit. Regression equations of the dependence of the company's profit on various factors are compiled. The research methods used were business activity analysis, correlation and regression analysis, research on cyclicity and on the presence of a trend in a time series. The greatest attention should be paid to increasing the cost of sales, since an increase in the cost of sales by 1 ruble entails an increase in profit by 0.92 rubles. The study of the dependence of the company's profit on time (24 months) showed that the profit changes randomly, there is no clear trend to decrease or increase it. In addition, no different cyclical fluctuations were detected. The analysis of business activity showed that the company is heading for its development.
\end{abstract}

\section{Introduction}

As you know, applied mathematics is a branch of mathematics that considers the application of mathematical methods in various fields of knowledge, for example, in medicine, economics, technical sciences, etc. Currently, it is impossible to imagine any industry that would work without the use of mathematical calculations, mathematical models.

Applied mathematics begins its development at the beginning in the late 19th and early 20th centuries, at this time there is a great leap in the development of technology. A. N. Krylov «Lectures on approximate calculations» can attribute one of the first works in this field to the book. In 1948, the authors Karman T., Bio M. published the book "Mathematical methods in Engineering". An important stage in the development of applied mathematics in Russia was the organization of the Institute of Applied Mathematics (IPM RAS) [1]. It was created to solve computational problems related to state programs of nuclear and thermonuclear energy, space exploration and rocket technology. The Institute is a part of the Department of Mathematical Sciences of the Russian Academy of Sciences. The main activity of the Institute is the use of computer technology to solve complex scientific and technical problems of great practical importance.

\footnotetext{
*Corresponding author: vinmarvlad@yandex.ru
} 
Modern applied mathematics is a special kind of science, standing on the edge between the exact, humanitarian and experimental sciences, boldly applying the techniques developed in each of these groups of sciences, if they are effective. This is the only way it can be, if its task is not to contemplate abstractions, but to actively intervene in life [2].

In addition to the direct purpose of applied mathematics, its elements are used by many teachers in the study of mathematics, both in school and in secondary vocational and higher education [3-12]. At the same time, the problems of applied orientation are often considered, which activates the processes of understanding, stimulates the semantic assimilation of topics, sections of the discipline; in professionally oriented educational situations, professional knowledge and competencies are assimilated and updated, experience in the implementation of knowledge is acquired, and the formation of meaningforming professional motives takes place.

Under the tasks of an applied nature, the problems are considered, the content of which reveals the applications of mathematics with related disciplines, linking their conditions with the use in the economy of modern production, in the service sector, in everyday life, in the performance of labor functions. Problems of applied mathematics can be used for different purposes, they can interest or motivate, develop mental activity, explain the relationship between mathematics and other disciplines. As practice shows, students who are at any stage of education, whether it is a school, technical school, or university, with great interest solve and perceive problems of applied content, because for the vast majority of the value of mathematical education is its practical capabilities. In the course of solving practical problems, students observe with interest how a theoretical problem arises from a practical problem, and how a purely theoretical problem can be given a practical orientation.

In our opinion, an applied task describing a specific production situation should reflect the content of the discipline, its main goal and objectives, and be a key component of training future specialists. The ways of solving the problem should be close to the practical techniques and methods that use the mathematical and non-mathematical apparatus and their integrative approach to solving this problem.

One of these tasks is the task of evaluating the effectiveness of the enterprise. In the modern economic literature, there are many different approaches to assessing the effectiveness of an enterprise. This procedure is carried out in order to determine a set of measures for a comprehensive analysis of the organization, aimed at a detailed study of the main indicators of the enterprise. In the course of the assessment, it is found out how effectively the company carries out its activities, what is its level of profitability, profitability, and determines the future prospects for development. The essence of the problem of improving the efficiency of the enterprise is to increase the economic results for each unit of costs, production resources in the process of their use.

Mathematical methods are widely used in solving economic problems of applied significance. These methods are based on mathematical modeling, the purpose of which is to find the most suitable, optimal solutions when using certain resources. Mathematical methods are the most important tool for analyzing economic data whose phenomena and processes are built on the basis of theoretical models. With their help, it is possible to display existing relations in economic life, predict the behavior of subjects and economic dynamics.

Today, there are many different models for evaluating the performance of an enterprise, including the correlation and regression model, which analyzes the financial condition of the enterprise to obtain further recommendations for improving the financial condition of the enterprise.

The evaluation of the efficiency of an enterprise based on regression analysis determines the form of relations that establish quantitative relationships between the 
random variables of the process under study, which characterize the real process of change. Regression analysis of indicators shows the state of dependence of factors that affect each other. The influence of factors on the main economic indicators of the enterprise is studied by the methods of correlation and regression analysis. The use of timely analysis using a correlation and regression model allows you to determine the relationship between several factors of activity and assess the degree of interdependence of the selected criteria for the analysis of the enterprise. The use of this type of analysis is based on the construction of a number of dynamics of changes in indicators, which is the most rational and allows you to most accurately assess the economic processes of changes in the company's indicators for a certain period.

\section{Materials and methods}

An integrated approach is the most optimal and high-quality approach to assessing the effectiveness of an enterprise. An integrated approach means a systematic comprehensive study of the financial condition of an enterprise, which allows for a comprehensive assessment of the financial performance of an organization that meets the information needs of a wide range of users, in order to assess the quality of its activities. The integrated approach includes a variety of methods: trend, comparative, factorial, the method of financial coefficients, vertical (structural) and horizontal (time) analysis of the balance sheet and the income statement [13].

For a qualitative assessment of the effectiveness of the Individual entrepreneur Glukhikh L. P., we used:

- Analysis of business activity, which allows you to characterize the results and effectiveness of the current core business of the enterprise;

- Correlation and regression analysis. Correlation analysis is one of the main methods of statistical analysis of the relationship of several features. This method is used when the observations are random and selected from a general set of influence factors. The main task of correlation analysis is to evaluate the regression equation. Regression analysis defines the analytical relationship between changes in the performance attribute and the influence of one or more factor characteristics that affect the performance attribute, which are taken as constant and average values.

- Research on cyclicity and on the presence of a trend in the time series.

\section{Results and discussion}

Mathematics is one of the few disciplines, each section of which allows you to perform In this study, we will consider one of the economic indicators - the efficiency of the enterprise. As an object of research, we will choose small forms of entrepreneurship on the example of individual entrepreneur Glukhikh L. P. Individual entrepreneur Glukhikh L. P. offers financial and accounting services to legal entities, individuals, entrepreneurs, partnerships and other legal entities. Clients are businesses that have found it economically and organizationally appropriate to purchase accounting services and financial advice outside of their structure. The company also works with individuals and provides both long-term services and one-time services. Long-term services include services such as monthly accounting, which includes many other services, such as processing bank statements, entering invoices, accounting transactions, cash receipts and spending orders, and much more. Short-term services are services that are provided only once and do not require a permanent contract for accounting services. Short-term services include such services as, 
for example, an annual accounting report for small businesses, and financial analysis of the company, various consultations, and more.

Table 1. Main indicators of the activity of the sole proprietor individual entrepreneur Glukhikh L. P.

\begin{tabular}{|l|c|c|}
\hline \multicolumn{1}{|c|}{ Indicators } & 2018 год & 2019 год \\
\hline $\begin{array}{l}\text { Revenue from accounting services provision of services } \\
\text { (thousand rubles) }\end{array}$ & 315 & 5736 \\
\hline Management expenses (thousand rubles) & - & $(652)$ \\
\hline Gross Profit (thousand rubles) & 270 & $(1902)$ \\
\hline Profit (loss) from sales & 270 & $(2556)$ \\
\hline Net profit (loss) & 240 & 826 \\
\hline
\end{tabular}

The analysis of business activity carried out in the table 1 , shows that revenue from the provision of services in the field of accounting for the provision of services in 2019 compared to 2018 increased by 5,421 thousand rubles, and gross profit decreased by the result, which amounted to 2,172 thousand rubles.

Management expenses in the sole proprietor of individual entrepreneur Glukhikh L. P. in 2018 were absent, and in 2019 amounted to 652 thousand rubles, which may indicate the active development of the sole proprietor of individual entrepreneur Glukhikh L. P. In general, the net profit of the sole proprietor of individual entrepreneur Glukhikh L. P. increased by 586 thousand rubles in one year.

Consider the model of dependence y-profit (loss) from the main activity of individual entrepreneur Glukhikh L. P. on various factors: $x_{1}$-accounts payable to suppliers, $x_{2}$-cash receipts, $x_{3}$ - cash outflows, $x_{4}$-customer debt, $x_{5}$-tax arrears to the budget, $x_{6}$-cost of sales, $x_{7}$-revenue. All indicators are measured in rubles.

Consider Table 2, a matrix of pairwise correlation coefficients for all variables involved in the analysis. The matrix is obtained using the Correlation tool from the Data Analysis package in Microsoft Excel.

Visual analysis of the matrix allows you to set:

1. Profit has a high pair correlation with factor $x_{6}$-cost of sales, and a moderate pair correlation with factors $x_{1}$ - accounts payable to suppliers.

2. Some variables of the analysis show quite high pair correlations, which requires checking the factors for the presence of multicollinearity between them. Moreover, one of the conditions of the classical regression model is the assumption of the independence of the explanatory variables.

To clarify the significance of the factors under consideration for inclusion in the regression model, we conducted a systematic selection of factors by excluding statistically insignificant variables from the model (Table 3). The significance of the factors was checked using the Student's criterion. In accordance with the general approach, at the first stage of systematic selection, all available factors were included in the model, that is, in our case, a seven-factor regression was considered.

Table 2. Matrix of pair correlation coefficients.

\begin{tabular}{|l|l|l|l|l|l|l|l|l|}
\hline & $y$ & $x_{1}$ & $x_{2}$ & $x_{3}$ & $x_{4}$ & $x_{5}$ & $x_{6}$ & $x_{7}$ \\
\hline$y$ & 1 & & & & & & & \\
\hline
\end{tabular}




\begin{tabular}{|l|l|l|l|l|l|l|l|l|}
\hline$x_{I}$ & $-0,34$ & 1 & & & & & & \\
\hline$x_{2}$ & $-0,16$ & $-0,140$ & 1 & & & & & \\
\hline$x_{3}$ & $-0,16$ & $-0,141$ & 0,999 & 1 & & & & \\
\hline$x_{4}$ & 0,0167 & $-0,313$ & 0,1166 & 0,118 & 1 & & & \\
\hline$x_{5}$ & $-0,258$ & 0,056 & 0,7243 & 0,721 & $-0,09$ & 1 & & \\
\hline$x_{6}$ & 0,995 & $-0,3315$ & $-0,159$ & $-0,159$ & $-0,034$ & $-0,264$ & 1 & \\
\hline$x_{7}$ & 0,0086 & $-0,277$ & 0,0955 & 0,096 & 0,963 & $-0,04$ & $-0,029$ & 1 \\
\hline
\end{tabular}

Table 3. Fragment of a seven-factor regression analysis.

\begin{tabular}{|l|c|c|c|}
\hline & & $\mathrm{t}$ tabl $(0.05 ; 12-7-1=4)$ & $\mathbf{2 . 7 7 6}$ \\
\hline$y$ & Coefficients & Standard error & $t$-statistics \\
\hline$x_{1}$ & $-186147,9721$ & 127203,8606 & $\mathbf{- 1 , 4 6 3 3 8 3 0 3 9}$ \\
\hline$x_{2}$ & 0,0041449 & 0,091269735 & $\mathbf{0 , 0 4 5 4 1 3 7 3 6}$ \\
\hline$x_{3}$ & $-902,9750495$ & 1531,986802 & $\mathbf{- 0 , 5 8 9 4 1 4 3 7 9}$ \\
\hline$x_{4}$ & 895,3687933 & 1519,482229 & $\mathbf{0 , 5 8 9 2 5 9 1 4 1}$ \\
\hline$x_{5}$ & 0,265558436 & 0,162991852 & $\mathbf{1 , 6 2 9 2 7 4 3 0 9}$ \\
\hline$x_{6}$ & 0,898884346 & 1,444986427 & $\mathbf{0 , 6 2 2 0 7 1 1 3 5}$ \\
\hline$x_{7}$ & 1,110607206 & 0,30689909 & 3,618802543 \\
\hline
\end{tabular}

Because of the audit, the factor $x_{1}$ - accounts payable to suppliers-was excluded, and it turned out to be the least significant. When considering the six-factor regression, the factor $x_{3}$ - cash outflow-turned out to be statistically insignificant. Continuing the verification process, we came to the conclusion that the equation with one factor $\mathrm{x} 6$ - the cost of sales, has a statistically significant coefficient before the factors, and, therefore, the factor $\mathrm{x} 6$ itself is statistically significant.

Thus, because of step-by-step selection, a one-factor regression equation is obtained, all the coefficients of which are significant at a 5\% significance level, of the form

$$
y=18607,89+0,92 x_{6} \text {. }
$$

The resulting equation of the dependence of profit on the cost of sales shows that with an increase in the cost of sales by 1 ruble, the profit of individual entrepreneur Glukhikh L. $\mathrm{P}$. will increase by an average of 0.92 rubles per month. 
We will evaluate the level of accuracy of the model. The level of accuracy of the model characterizes the degree of deviation in the average of the actual values of the resulting variable y (profit) from its values obtained by the regression model (predicted). To assess the level of accuracy, various errors are used: average relative, standard, and others.

The standard error of the model is displayed in the first table "Regression statistics" of the regression analysis report of the Data Analysis package in Microsoft Excel. For our one-factor model, this table is shown in Fig. 1.

\begin{tabular}{lc}
\hline Regression statistics & \\
\hline Multiple R & 0,995350512 \\
R-square & 0,990722641 \\
Normalized R-square & 0,989794905 \\
Standard error & 157062,6155 \\
Observations & 12 \\
\hline
\end{tabular}

Fig. 1. A fragment of regression analysis for a single-factor model.

The better the accuracy of the model, the smaller its standard error. The standard error of the Se model is compared with the standard error of the resulting feature y (standard deviation) - Sy. We will find the standard error of the resulting attribute $y$ in Excel using the statistical function STANDOTKLON.

During the calculations, we got the standard error of the model equal to 157062.6155 , and the average square deviation of the effective feature (profit) is 1554763.355 . Since $\mathrm{Se}<$ Sy, the one-factor regression model is accurate.

Thus, because of studying the dependence of the profit of individual entrepreneur Glukhikh L.P. on seven different factors, we found that the greatest attention should be paid to increasing the cost of sales, since an increase in the cost of sales by 1 ruble entails an increase in profit by 0.92 rubles.

The study of the dependence of the company's profit on time (24 months) showed that the profit changes randomly, there is no clear trend to decrease or increase it. In addition, no different cyclical fluctuations were detected.

\section{Conclusions}

The activity of any enterprise is aimed at achieving the main goal -making a profit. In addition, the main ally in the direction of achieving this goal is the "efficiency" category. For each enterprise with its own organizational and management structure and functioning technology, individual methods and approaches are needed.

As a result of the analysis of the assessment of the efficiency of the enterprise, the main directions of work to improve the competitiveness of the Individual entrepreneur Glukhikh L. P. were identified, which include:

1. Management improvement, professional development. It is no secret that the driving force of any enterprise is its qualified employee. An accounting specialist is a specialist who maintains accounting records in a company, is engaged in document management, preparation and submission of accounting and tax reports to regulatory authorities, and 
since our legislation is constantly changing, in order to maintain the qualifications at a sufficient level, accountants must constantly improve them.

2. The establishment of a flexible pricing policy, a system of discounts, motivating the client to return to this particular service provider.

3. Increase the level of advertising activity to attract new customers. Creating your own website is an effective advertising for business, which is able to work reliably and stably for you and your company for many years.

4. Digitalization of the business or the process of introducing the latest technologies into the activities of the enterprise, as well as deep transformation of products, readiness for complex changes that affect the culture of the enterprise, correct management and external communications, can lead to lower costs, therefore, to an increase in profits.

5. Periodic analysis of the outflow of customers will help to draw conclusions about the shortcomings in the work and how to eliminate them.

6. Introduction of a number of additional services.

\section{References}

1. K.I. Babenko, On the works of M. V. Keldysh on Mechanics (1981)

2. E. S. Wentzel, Mathematics about mathematics: collection of articles (1984)

3. M. Vinogradova, N. Malchukova, S. Dorofeev, Journal of Physics: Conference Series, 201 (2019)

4. I.V. Tolstoukhova, Y.V. Kryucheva, L.I. Iakobiuk, S.V. Kulikova, Humanities and Social Sciences Reviews, 7(4) (2019)

5. N.V. Biryukova, Espacios, 39(20) (2018)

6. N. Biryukova, E3S Web of Conferences, 222 (2020)

7. M.V. Vinogradova, L.I. Yakobyuk, N.V. Zenina, Espacios, 39(30) (2018)

8. L.I. Iakobiuk, M.V. Vinogradova, N.N. Malchukova, Y.V. Kryucheva, Espacios, 38(40) (2017)

9. Y.V. Kryucheva, I.V. Tolstoukhova, L.I. Iakobiuk, M.V. Vinogradova, International Journal of Engineering and Technology(UAE), 7(4) (2018)

10. M.V. Vinogradova, L.I. Iakobiuk, International Transaction Journal of Engineering, Management, \& Applied Sciences \& Technologies, 11(10) (2020),

11.E.A. Semizorov, N.Ya. Prokopiev, S.V. Solovieva, E.N. Dergousova, V.I Nazmutdinova. S.V. Romanova, N.I. Koshkarova, A.I. Rakoca, V.A. Bomin, S.A. Utusikov, International Journal of Applied Exercise Physiology, 9(12) (2020)

12. L.I. Yakobiuk, The world of science culture and education, 5(84) (2020)

13. I.I. Moiseeva, Bulletin of TSU, 6 (2017) 